\title{
Befriending the foe: Towards an instructional model on utilizing the social media in the classroom
}

\author{
Montebon, Darryl Roy T. $\bowtie$ \\ Philippine Normal University, Philippines (montebon.drt@pnu.edu.ph)

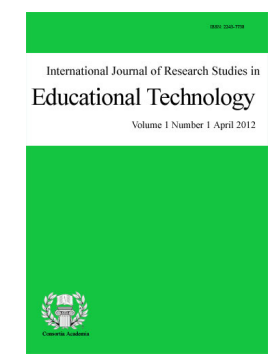

Accepted: 17 October 2016

ISSN: $2243-7738$ Online ISSN: 2243-7746

OPEN ACCESS

\section{Abstract}

The role of the social media has expanded from just establishing a network of friends to different areas such as business, entertainment, and even education. While the challenge stands for every teacher to win the students against too much exposure to social media, this research seeks to help teachers be informed on how they can utilize the social media for classroom advantage. This qualitative research investigates on the experiences and perceptions of pre-service teachers who are going to be future literature teachers as they prepare lessons using Facebook, implement their plan, and assess student learning. While there are several researches that are available on the effect of the social media in the classroom, this research presents how the social media can do so when it is utilized as a main platform for instruction and not just for supplementary activity. The responses gathered from the questionnaire given to the pre-service teachers were analyzed as to the framework of Bexheti, Ismaili, and Cico (2014) that social media affect the different areas of classroom activities in content, creation, connection, and collaboration. This research found out that the experiences and perceptions of students are positive in general with some challenges identified. It can be deduced that the social media when utilized as medium of instruction for teaching can motivate the 21 st century to study literature. An instructional model called MEDIA was designed after the analysis of the research results.

Keywords: social media in the classroom; Facebook; modern teaching of literature; media model for classroom instruction using social media 


\section{Befriending the foe: Towards an instructional model on utilizing the social media in the classroom}

\section{Introduction}

The age of technology where information is just a one click away makes teaching in the 21 st century a challenging task that calls for pedagogical innovations to utilize the power of technology. Students who are digital natives have technological skills that can influence their view on how to learn different things in and out of school. One of the many available technologies for the present day learners is the social media. The social media is a product of the social software movement that utilizes the internet to support collaboration, community building, active participation and sharing (Junco, Heibergert, \& Loken, 2010). Such function of the social media can be made possible through wikis, blogs, media sharing tools, networking platforms and virtual worlds (Bryer \& Zavatarro, 2001).

However, the role of social media in the society has expanded from just mere social interaction and information dissemination to a more powerful endeavor like education (Ferriman, 2013). In view of the 21st century teaching and learning, more teachers have acknowledged the power of the internet over the lives of the present day learners. Thus, to make use of the digital skills of the students to their advantage, the use of social media in the classroom has been explored by educators (Ebner, Lienhardt, Rohs, \& Meyer, 2010). In a survey conducted by Seaman and Tinti-Kane (2013) as commissioned by Pearson Learning Solutions, they have found out that the use of social media by higher education professors have increased by $21.3 \%$ from years 2012 to 2013 . The said increase in the utilization of social media in the classroom is due to the perception of teachers that it can increase student motivation in class because of the interactive nature of the method. Therefore, educators have seen that social media utilization in the classroom significantly impacts student-teacher communication.

The social media can be an enemy of teachers in the classroom because it distracts students' attention towards the lesson. It makes students out of focus towards class activities. It can also be a venue for other online activities that are beyond classroom purposes. This study aims to help teachers in 'befriending' the enemy and make it work to their advantage. Guy (2012) stressed that although there is a worldwide increase on the use of social media for personal purposes; educators are slow in using it for academic endeavors. Hence, this research is an attempt to investigate the effects of the social media the teaching and learning process when it is used as medium for teaching literature and not just for academic support as experienced by the preservice teachers.

According to Chen and Bryer (2012), teachers perceived that role of the social media in education is informal and self regulated, where participation is optional. In contrast to such perception, the present research reports the experiences of pre-service teachers as they undergo the process of preparing lessons and executing them using the social media, the Facebook in particular, in their formal instruction. The methods of using the Facebook in their classroom instruction is not informal but is structured and has been carefully planned how it can be utilized formally in teaching literature. It is the goal of this research to further inform educators on the benefits and disadvantages of using social media in classroom instruction. The present research contributes new knowledge how the traditional pedagogy in literature can be enhanced using the social media.

\section{Review of Related Literature}

\subsection{The Social Media in Education Context}

There are different social media platforms that teachers utilize in the classroom. According to Vikers, Field, and Melakoski (2015), the social media does not only allow students to receive broadcasts but make them 
interact with the information and even create new content. Therefore, it is suggested that educators should consider the potential of blending the social media and other form of technology with their traditional pedagogies. Utilizing the social media in the teaching and learning process gives leverage to the open communication between teacher and students; strengthen social ties, and the production of new knowledge and media content. Seaman and Tinti-Kane (2013) identified several platforms namely blogs and wikis, podcasts, Twitter, LinkedIn, and Facebook. The said platforms allow students to do different activities like creating narratives and visual outputs, adding comments on issues and questions, reading, watching videos, and even listening to podcasts. Such activities are viewed to engage students in classroom activities.

Bexheti, Ismaili, and Cico (2014) summarized the role of the social media in the teaching and learning process in four dimensions which are:

D Content. The social provides students with free and accessible knowledge that can lead them to become lifelong learners. It also equalizes the learning opportunity for every student and subject preparation for Higher Education institutions.

$>$ Creation. The use of social media in the classroom enables students to produce digital contents on their own and even publish it online which makes it beneficial for both the learners and the teachers, thus, encouraging more active and proactive approaches to learning.

$>$ Connecting. The ease to share and to access other information is one of the benefit of using the social media in the classroom. It allows students to connect with other students or teachers around the world where they can get specific knowledge in their field of interest.

$>$ Collaboration. Teachers and students can work together and achieve a certain goal through social media. Thus, using social media in the classroom encourages the pooling of resources and gathering of experts towards a common objective.

However, several concerns have been raised by teachers who utilized the social media in their instruction. Based on the result conducted by Seaman and Tinti-Kane (2013), most teachers are concerned with the integrity of student outputs. Since, the internet offers a wide range of information that can be easily accessed, teachers should carefully check the authenticity of the materials submitted by students. Another concern of teachers is the privacy of the class discussion and of the student as well. The teacher will find hard to control the people that are participating in class discussion using the social media. Teachers should carefully chose an internet platform where only students that are part of the class can participate and no outsiders can join the discussion and even view the class' outputs. Thus, teachers suggest that social media accounts for class and personal use should be defined. Other concerns for utilizing the social media in the classroom include grading and assessment, inability to measure effectiveness of the pedagogy, the time it to learn or use the platform, and the lack of support of the respective institution.

Among the different social media platforms, Facebook has been the least social media platform that was utilized by teachers. Such perception on the utilization of Facebook in the classroom has been supported by other researchers (Bexheti, Ismaili, \& Cico, 2014; Lederer, 2012). Teachers pointed out that using Facebook in the classroom diverts students' attention from the class. Most of the students and teachers agreed that using online and mobile technologies are more distracting than helpful to students for academic work (Seaman \& Tinti-Kane, 2013) Andersson, Hatakka, Grönlund, and Wiklun (2012), through investigating the experiences of teachers and students, agreed with such observation of the respondents of the survey. In their study, students themselves reported in the interviews that once they get in the social media like Facebook in the classroom they found it hard to get away. Teachers and students had the same observations that some students, particularly those that are uninterested with the lesson are the ones using Facebook as a means of distraction. Teachers perceived that they are up to war with technology and that they don't know how to win it. Andersson et al. (2012) believed that for teachers to successfully utilize the social media for their advantage; there should be regulations to fully control 
Montebon, D. R. T.

the situation and for students to differentiate when to use social media for leisure or for educational purposes.

\subsection{Purpose of the Study and Conceptual Framework}

This qualitative research aims to explore the experiences of the pre-service teachers in facilitating literature class using the social media as a platform for discussion rather than the traditional mode of teaching the literature subject. The social media promise a great potential in motivating students in the classroom since it plays active part in their lives at present time. Therefore, this study was conducted to develop a pedagogy that can help teachers to motivate students in studying literature and allow them to participate better in the classroom. In this research, the social media being referred is Facebook or colloquially called by its acronym FB. Furthermore, this study adapts the study of Bexheti, Ismaili, and Cico (2014) on the effects of the social media in the classroom. Figure 1 below shows the conceptual framework that guides this study on the determining the effects of FB in the classroom.

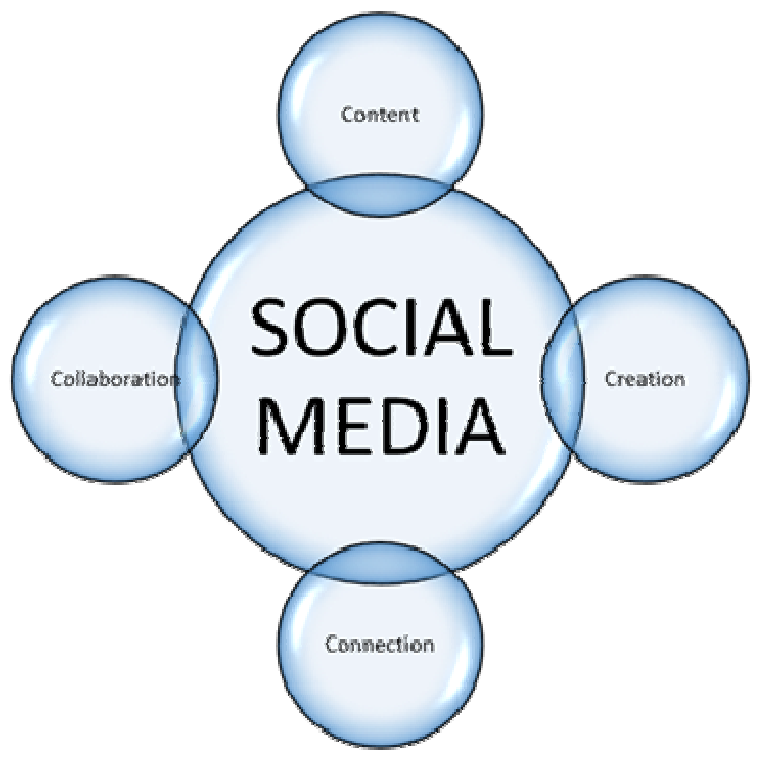

Figure 1. Conceptual Framework on the effects of social media in facilitating learning in the classroom (Bexheti, Ismaili, \& Cico, 2014)

\section{Methodology}

This research utilized a qualitative search design. The respondents were given a questionnaire that investigates their perception and experience on using the social media as a platform of instruction for teaching literature. Below were the specific questions asked by the researcher to the respondents.

$>\quad$ How do you find teaching literature using the social media?

$>$ How is teaching literature using the social media different from the traditional way of teaching the subject?

$>\quad$ What are the benefits and challenges that you have observed upon teaching literature using the social media?

The respondent of this research are the seventeen pre-service teachers, two males and fifteen females, taking bachelor of science in teaching literature (English strand). The ages of the respondents range from 18 t0 23 years old. The respondents are students of the researcher in the professional education course on principles and methods of teaching. As a final requirement for the course, the respondents were asked to prepare literature lessons using Facebook as the platform of discussion rather than the traditional literary manuscripts. The 
Befriending the foe: Towards an instructional model on utilizing the social media in the classroom

implementation, observation, and data gathering happened on the first semester of school year 2015-2016.

The respondents were grouped into four and each group chose a literary lesson that they will prepare and demonstrate in class. The topics that were chosen by each group and one of them is the Seven Ages of Man by Shakespeare (1616) and for the purpose of discussing how the lesson execution proceeded in this research, the topic Seven Ages of Man will be utilized as an example. As the class starts, the group allowed the participants to open their Facebook page and directed them in the group site that they have purposely created for the lesson. In the Facebook page, there were graphic illustrations that depict each stage in the Seven Ages of Man. At first, the respondents were allowed to scan the illustrations and identify words that are not familiar to them. Respondents placed the identified words on the comment section and the teacher provided the clarification by replying to the comment and provided internet links where they can clarify the concept of the said words.

The teacher then projected the FB page on the board and the class read each line in the illustration. In every illustration, the teacher asked the participants to share what the lines meant to them. The respondents shared their views and opinions on the lines presented by making 'comments' in each picture. The teacher then 'replied' to certain comments that were made. The demonstration teachers asked the participants "In what stage are you now according to the poem Seven Ages of Man?" and they answered the 'lover'. The demonstration teacher then provided an activity for the participants where the concept of the 'lover' stage can be applied. The participants analyzed the situation and made their comments about it. To extend the discussion, the participants were tasked to make PowerPoint presentations on how the Seven Ages of Man apply to their personal life. The presentation that they made should be posted on the FB page provided by the teacher. After the demonstration, the participants critiqued the work of the demonstrating teachers and suggested how their work can be improved. The respondents then answered the questionnaire provided by the researcher to gather perceptions and experiences of teachers on using the social media as a platform for instruction in teaching literature.

\section{Results}

Utilizing the social media, the Facebook in particular, has a number of effects to the teaching and learning process. This section of the present research discusses the said effects as observed by the participating pre-service teachers.

\subsection{Perceived Effects on Students}

The Table 1 below reports the perceived effects on students of utilizing social media in teaching literature by pre-service teachers.

\section{Table 1}

Perceived Effects on Students $(N=17)$

\begin{tabular}{lcc}
\hline \multicolumn{1}{c}{ Response } & Frequency & Percentage \\
\hline Interactive & 7 & $41.7 \%$ \\
Fun and enjoyable & 7 & $41.18 \%$ \\
Motivates students & 5 & $29.41 \%$ \\
Innovative & 5 & $29.41 \%$ \\
Student-centered & 4 & $23.53 \%$ \\
Convenient & 3 & $17.65 \%$ \\
\hline
\end{tabular}

Note. Answers have been repeated

Based on table 1 above it can be deduced that using social media in teaching literature has been perceived by pre-service teachers to promote more interaction between students and teachers (41.7\%). Respondent No. 15 said that "Using FB in our lessons makes our lessons interactive. The students enjoy that they can 'like' photos and posts about our lesson. They can also post questions on our topic and comment on some answers by their 
classmates." The interactive nature of the social media also promotes collaboration within students. Comparing the traditional way of teaching literature with the use of social media in instruction, Respondent 5 said that it is evidently different "It is different since in the traditional way of teaching literature, students easily lose their focus. By using the FB and incorporating its social nature, the collaboration of ideas come alive”.

The respondents also acknowledged that utilizing the social media in their literature lessons make their classes cool, fun, and enjoyable (41.7\%). Respondent 1 said that using FB in the classroom is really fun compared to the traditional method since students find the activities interesting. Respondent 5 agreed that using social media in literature class is fun and draws the attention of student since the students are evidently into social media.

The social media is also effective in promoting students' motivation towards the subject matter (29.41\%). Respondent 9 described that "Through FB, you can prepare different activities for your students that make them more encouraged and energized to study the lessons in literature. Hence, students learn better and faster”.

The relatively new pedagogy in teaching literature has been found by pre-service teachers as an innovation in teaching the discipline $(29.41 \%)$ and that it is a method which is student-centered (23.53\%). Respondent 11 stressed that with the new method of teaching literature it can be said that 'students learned something'. Her experience is described below.

"The social media are not primarily designed for academic matters. But it is a good thing that it has been utilized in the classroom because it promotes learning. Of course, the FB in literature class is a new strategy for teaching/learning and it gives much emphasis on student's own way of learning that makes the method of teaching student-centered.”-Respondent 11

The convenience that the social media offer to the teaching and learning process had also been noticed by the respondents. "Using FB as the channel of learning is fun and quite convenient since most of the students have their own FB accounts that they can easily access. In literature, there are various ideas that may struck students' minds due to their interpretation of the literary piece. Using FB help them to share and rationalize their ideas through the different features of FB like 'comment' and 'replies'. " said Respondent 2. Reasons like easy feedback system between teachers and students have also been observed.

\subsection{Perceived Effects on Teaching}

The use of social media in teaching literature has various effects on the teaching process as perceived by the respondents of this study. The following paragraph describes the experience of respondent 5 on using FB as a medium of instruction in teaching literature.

"To teach using FB is different since in all honesty, literature is really traditionally taught that affect students motivation towards the subject. Using FB in class is fun and convenient to both students and teachers. The use of FB in class saves time and for the teachers and make them accomplish more work. In terms of teaching preparation, it is easier since the medium is advanced, easy to manipulate, and has high quality. Writing and implementing the lesson plan is easier because of the flexibility of the medium. However, because of some technical problems that may be encountered, the learning plan should be versatile which should also ensure that the implementation of the lesson plan should not be rigid." - Respondent 5

The experience of Respondent 5 represents most of the responses gathered on the effects of using social media in the literature classroom. Respondents acknowledged that the modern way of teaching literature through social media minimizes the boredom felt by students in studying the subject. Such notion arise from the perception that social media offers varied resource materials like pictures, videos, and even audios that they can utilize in teaching the literature. The availability of materials online enabled the respondents to manage their 
time efficiently while they prepare for their demonstration day. The respondents appreciate that the visuals they used in class are virtually presentable because of the quality of the materials available online or the materials that students can create and share through the social media. An example of such experience would be the 'selfie' pictures and PowerPoint presentations uploaded by the participants in one of the activities that were done during the lesson.

With such teaching experiences, the respondents were able to realize the using social media in classroom instruction particularly literature supports the different theories of learning like constructivism, connectionism, and cognitivism. Respondent 10 that said that constructivism is evident in using FB in class because they have to use their 'schema' of what is presented in the lesson through the use of FB. Connectionism has been recognized by Respondent 16 since the students use their previous knowledge and connect them with that of their classmates and teachers through social media. Respondent 4 on the other hand recognized that the cognitive aspect of students' learning is the theory that is evident in using social media in the classroom because the learners have to thinks carefully on how to answer the question in each task critically and creatively.

Though most responses are for the use of social media in teaching literature, some respondents disagreed. Below is a sample response that depicts the disagreement.

"Literature is the soul of art and I think using literature discussion and Facebook is not a good idea for it somehow distracts the students and it disregards the very core of literature which is food for the searching soul" - Respondent 8

The response of Respondent 8 falls on the personal belief of a teacher on how to teach the subject. However, his reason for disagreeing has been observed by other pre-service teachers as well. Some respondents (23.5\%) said the nature of the social media can be distracting to students. The continuous updates of newsfeeds can affect the attention of students towards the lesson. The hesitation of Respondent 8 towards utilizing the social media in literature classes may also arise from one of the major concerns raised by $35 \%$ of the respondents which is the technical nature of the pedagogy. Since the social media is a key to the investigated pedagogy, computer units with internet access is a must. The respondents stressed that the teacher should have plan B when the internet connection is too slow or not working and even if there is no computer or if there are no electronic gadget available.

The respondents also feared that the students output may not be authentic since the internet provides almost unlimited resources of information. Using the social media in the classroom entails more responsibility to the teacher to check further the originality of the output of the students. Other factors that may hinder teachers utilization of the social media in the classroom includes preparation time for the activities and availability of materials.

\section{Analysis and Discussion}

The results showed that the use of social media, the FB in particular, as a formal method of teaching literature has effects on the teaching learning process. The respondents of this research acknowledged that utilizing the social media entails some advantages and disadvantages in the classroom. According to the research of by Bexheti, Ismaili, and Cico (2014) there are four themes by which teachers perceive the effects of social media in the classroom. These are content, creation, connecting, and collaboration. The result of the present research on the perception of pre-service teachers in their experience on the pedagogy can be analyzed using the same themes with that of Bexheti, Ismaili, and Cico (2014).

On Content. According to Bexheti, Ismaili, and Cico (2014) the use of social media in the classroom provides learners with free if not limited access to information. In the present research, the use of social media in teaching literature as perceived by the pre-service teachers improves their content delivery because the materials that they have used are presented in a form that students can easily access to. It enables pre-service teachers to 
Montebon, D. R. T.

prepare lessons conveniently because they no longer need to prepare the reading material using the traditional way in paper form. Teachers' visual presentation of their lesson is also presentable since more graphics can be used to enable students to visualize the literary text. Though pre-service teachers acknowledge that using social media in the classroom can be positive to learning the content of the lesson, this research could not empirically back up the claim due to the lack of data. Therefore, it is suggested that the pedagogy be further studied, and this time focus on student learning.

On Creation. Students' use of the social media in the classroom enhances their productivity and creativity. In this research, pre-service teachers agree that using the social media draws out the creativity of the students by conceptualizing what they will post on the FB page in response to the instruction of the teacher. Students were creative in taking 'selfies' and even in making powerpoint presentation in the activities that were utilized by the pre-service teachers. However, as other Seaman and Tinti-Kane (2013) would agree, the authenticity of the content of the material should always be considered. Since the use of the internet is a must for the pedagogy, teachers should check the originality of the material submitted by the students.

On Collaboration and Connection. The nature of social media involves constant contact with other people. In this research, the pre-service teachers have realized that using the social media for their class encouraged optimum class participation by making comments and posting creative work. The use of social media will enable students to work together, agree on what to present, and state their opinions on matters presented in class. In this regard, through collaboration, students become active partners in the learning process. For the teachers, the use of the social media in the classroom is also beneficial. As the pre-service teachers have discovered in this study, there are FB pages that have already been created for specific literature lessons. The internet also offers a variety of links that can be shared through FB that students can browse and perform activities.

\subsection{Implications on practice and on future research}

Based on the result of this research it can be deduced that the method of using the social media in the classroom, Facebook specifically, is a potential pedagogy that can be utilized to further motivate students to study literature. Literature teachers are encouraged to explore the pedagogy and determine if it can improve classroom situation. However, teachers should practice caution in using the proposed pedagogy. Teachers should design methods how to improve and safeguard students from getting distracted while participating class. It is also advised that teachers should be mindful in checking students' outputs for the internet as imperative to the pedagogy is a source of a wide form of knowledge that can be easily copied.

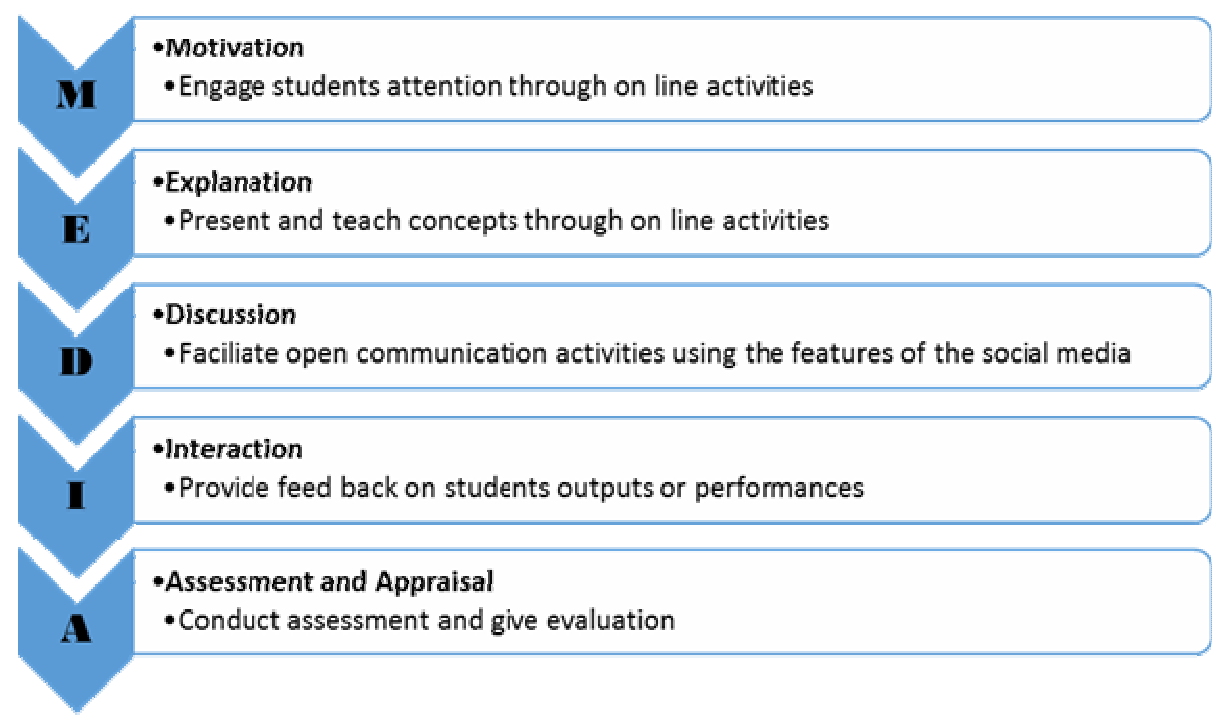

Figure 2. The MEDIA model in integrating the social media in the classroom 
Befriending the foe: Towards an instructional model on utilizing the social media in the classroom

For future research, it will be interesting to know what would make students copy the work on the web, investigate the reasons why would do it, and design a program that will help students inhibit or prevent doing the act. The concern of one respondent in the present research on deviating from traditional way of teaching literature can also be a good area for study. It will be interesting to determine if students prefer the use of social media in discussing literary text or they would still prefer reading it from books or paper. The said difference is believed to have impact on student learning. Further, based on the perception of pre-service teachers on the effects of the social media in teaching literature, the results of this research suggest that the social media can be specifically incorporated in the classroom pedagogies. Figure 2 above shows an instructional model that is proposed on how to go through with the said social media integration in the classroom.

The designed instructional model is an output of the ideas that have been generated from the present research. The features of the MEDIA instructional model can be easily integrated in the different disciplines that may opt to utilize the model. For future research, it is suggested that the MEDIA instructional model be further studied as to its validity and applicability on using other forms of social media.

\section{References}

Andersson, A., Hatakka, M., Grönlund, A. \& Wiklund, M. (2014). Reclaiming the students - coping with social media in 1:1 schools. Learning, Media and Technology, 39(1), 37-52. http://dx.doi.org/10.1080/17439884.2012.756518

Bexheti, L. A., Ismaili, B. E., \& Cico, B. H. (2014). An analysis of social media usage in teaching and learning: The case of SEEU. In Proceedings of the 2014 International Conference on Circuits, Systems, Signal Processing, Communications and Computers (pp. 90-94), Venice, Italy.

Bryer, T., \& Zavattaro, S. (2011). Social media and public administration: Theoretical dimensions and introduction to symposium. Administrative Theory \& Praxis, 33(3), 325- 340. http://dx.doi.org/10.2753/ATP1084-1806330301

Chen, B., \& Bryer, T. (2012). Investigating instructional strategies for using social media in formal and informal learning. The International Review of Research in Open and Distance Learning, 13(1), 87-100.

Ebner M., Lienhardt, C., Rohs, M., \& Meyer, I. (2010). Microblogs in higher education - A chance to facilitate informal and process-oriented learning. Computers \& Education, 55, 92-100. http://dx.doi.org/10.1016/j.compedu.2009.12.006

Ferriman, N. (2013). The Impact of blended e-learning on undergraduate academic essay writing in English (L2). Computers \& Education, 60(1), 243-253. http://dx.doi.org/10.1016/j.compedu.2012.07.008

Guy, R. (2012). The use of social media for academic practice: A review of related literature. Kentucky Journal of Higher Education Policy and Practice, 1(2), article 7.

Junco, R., Heibergert, G., \& Loken, E. (2010). The effect of Twitter on college student engagement and grades. Journal of Computer Assisted Learning, 27(2), 119-132. http://dx.doi.org/10.1111/j.1365-2729.2010.00387.x

Seaman, J., \& Tinti-Kane, H. (2013). Social media for teaching and learning. Boston: Pearson Learning.

Vikers, R., Field, J., \& Melakoski, C. (2015). Media culture 2020: Collaborative teaching and blended learning using social media and cloud-based technologies. Contemporary Educational Technology, 6(1), 62-73 
Montebon, D. R. T. 